This is the last draft sent to the Editorial by the authors of the article:

S. F. MEDINA, M. I. VEGA, M. GÓMEZ

"Influence of TiN Particles on Dynamic and Static Recrystallization in Microalloyed Steels"

Materials Science Forum

Vol. 467-470 (2004), Pages: 1205-1210

DOI: 10.4028/www.scientific.net/MSF.467-470.1205

ISSN: 0255-5476

To be published in Digital.CSIC, the Institutional Repository of the Spanish National Research Council (CSIC)

See more papers from the authors on:

$\underline{\text { http://digital.csic.es }}$

http://www.researcherid.com/rid/B-7922-2008 


\title{
Influence of TiN Particles on Dynamic and Static Recrystallization in Microalloyed Steels
}

\author{
S.F. Medina, M.I. Vega and M. Gómez \\ CENIM, Av. Gregorio del Amo 8; 28040-Madrid, Spain
}

Keywords: Microalloyed steels, dynamic and static recrystallisation, energy activation.

\begin{abstract}
This work has studied the influence of different Ti and N compositions on hot deformation strength by determining the peak stress of flow curves and the activation energy (dynamic recrystallisation). It has also assessed their influence on static recrystallisation by means of the statically recrystallised fraction versus time and the activation energy. A precipitate study performed by SEM and TEM has yielded a better understanding of the influence of the Ti/N ratio and precipitation state in hot deformation (dynamic and static recrystallisation). An agreement has been found for the finer distribution of precipitates, $\mathrm{Ti} / \mathrm{N}$ ratio close to 1.5 , smaller austenite grain, maximum activation energy for hot deformation (dynamic recrystallisation) and maximum activation energy for static recrystallisation.
\end{abstract}

\section{Introduction}

Titanium nitride particles (TiN) present very low solubility in austenite and their complete dissolution is not possible unless the reheating temperature is very high, close to the melting point of steel [1,2]. This characteristic makes Ti and $\mathrm{N}$ ideal elements for controlling the austenite grain size in processes involving the application of heat, such as the heat affected zone in welding. Besides possessing good weldability, structural steels must also have adequate strength and toughness.

The role of TiN particles in the control of austenite grain size is well known and the mechanism by which they exert this influence can be explained and interpreted by the Zener and Gladman expressions [3,4], which relate precipitate size, precipitated fraction and austenite grain size. A Ti/N ratio of between 1 and 3 yields good results in grain size control, especially when precipitation takes place in the solid state since finer precipitates are obtained [5-8].

On the other hand, it is known that the static recrystallisation experienced by austenite between passes in hot rolling is influenced by all the variables that intervene in rolling, such as the temperature, the reduction in each pass, the strain rate and the austenite grain size $[9,10]$. However, the quantitative influence of the $\mathrm{Ti} / \mathrm{N}$ ratio and their corresponding precipitation state is practically unknown.

The aim of this work has been to study the quantitative influence of the $\mathrm{Ti} / \mathrm{N}$ ratio on hot deformation strength and static recrystallisation, the latter being the main factor responsible for the microstructral evolution during rolling.

\section{Experimental Procedure}

Six steels were manufactured in a vacuum induction furnace from electrolytic iron of high purity. The steels can be classified into two groups (Table 1) according to their nitrogen content. One group contains three steels with 40 ppm nitrogen (steels S1, S2 and S3) while the other group consists of three steels with 80 ppm nitrogen (steels S4, S5 and S6). Steels S1 and S4 were alloyed without Ti in order to be used as references in the evaluation of this element's influence. 
The torsion specimens had a gauge length of $50 \mathrm{~mm}$ and a radius of $3 \mathrm{~mm}$ and were protected by an argon stream in order to prevent their oxidation. The torsion magnitudes -torque and number of revolutions- have been transformed into equivalent stress and strain according to Von Mises criterion [11]. Two types of tests were carried out. In order to obtain flow curves the specimens were initially heated to an austenitisation temperature of $1300^{\circ} \mathrm{C}$ for 10 minutes. The temperature was then lowered to the testing temperature of 900,1000 or $1100^{\circ} \mathrm{C}$ and an equivalent strain of 2.7 was applied, sufficient to produce the dynamic recrystallisation of the steel.

To determine the recrystallised fraction versus time, the method known as "back extrapolation" was applied [12]. Two austenitisation temperatures were applied: $1300^{\circ} \mathrm{C}$ and $1100^{\circ} \mathrm{C}$ for 10 minutes, respectively. The test was performed cooling rapidly from the austenitisation temperature to the deformation temperature: $900,1000,1100^{\circ} \mathrm{C}$. Two strain values were established, namely 0.2 and 0.35 , both being below the peak deformation in order to avoid dynamic recrystallisation.

The study of precipitation was carried out by Transmission Electron Microscopy (TEM) using the carbon replica extraction technique.

Table 1. Chemical composition (wt, \%) of the steels used.

\begin{tabular}{|c|c|c|c|c|c|c|c|c|}
\hline Steel & $\mathrm{C}$ & $\mathrm{Mn}$ & $\mathrm{Si}$ & $\mathrm{P}$ & $\mathrm{S}$ & $\mathrm{Ti}$ & $\mathrm{Al}$ & $\mathrm{N}$ \\
\hline S1 & 0.12 & 1.25 & 0.34 & 0.014 & 0.015 & 0 & 0.047 & 0.0040 \\
\hline S2 & 0.13 & 1.23 & 0.32 & 0.011 & 0.013 & 0.021 & 0.045 & 0.0046 \\
\hline S3 & 0.13 & 1.16 & 0.31 & 0.011 & 0.013 & 0.047 & 0.045 & 0.0043 \\
\hline S4 & 0.10 & 1.13 & 0.30 & 0.007 & 0.012 & 0 & 0.032 & 0.0080 \\
\hline S5 & 0.12 & 1.18 & 0.29 & 0.007 & 0.012 & 0.018 & 0.034 & 0.0080 \\
\hline S6 & 0.11 & 1.09 & 0.25 & 0.005 & 0.012 & 0.031 & 0.035 & 0.0083 \\
\hline
\end{tabular}

\section{Analysis of Precipitates}

In the precipitation study the size distribution was seen to vary between a few nanometres up to micrometres. For this reason it was necessary to divide the precipitates into two groups: fine ( $<100$ $\mathrm{nm})$ and coarse $(>100 \mathrm{~nm})$. The identification of the precipitates observed as TiN was performed by electron diffraction and X-ray dispersion analysis. The studied precipitation state was that corresponding to $1300^{\circ} \mathrm{C}$ in all the steels.

Fig. 1 shows a TEM micrograph of the precipitation state of steel S5 at $1300^{\circ} \mathrm{C}$ and Fig. 2 depicts the size distribution of the fine precipitates at this temperature. The distribution can be seen to be lognormal, i.e. it follows a logarithmic law that has the shape of a Gauss bell. Table 2 indicates the weighted mean size of the fine and coarse precipitates, respectively, for each steel.

Table 2. Values of weighted mean size of fine precipitates at $1300^{\circ} \mathrm{C}$ and holding time of $10 \mathrm{~min}$, and ratio $\mathrm{Ti} / \mathrm{N}$ for steels used.

\begin{tabular}{|l|c|c|c|c|}
\hline Steel & S2 & S3 & S5 & S6 \\
\hline Ratio Ti/N & 4.56 & 10.93 & 2.25 & 3.73 \\
\hline Size, $\mathrm{nm}$ & 23 & 65.2 & 13.8 & 14.1 \\
\hline
\end{tabular}


The $\mathrm{Ti}$ and $\mathrm{N}$ contents were also determined, both in solution and precipitated, as well as the precipitated volumetric fractions (Table 3), taking into account the solubility product of the TiN particles [1] and the expression for calculating the precipitated volume [13].

Table 3. Ti and $\mathrm{N}\left(\%\right.$, wt) as dissolved (s) and as precipitated (p), at $1300^{\circ} \mathrm{C}$ determined using the Turkdogan's solubility products.

\begin{tabular}{|c|c|c|c|c|}
\hline \multirow{2}{*}{ Steel } & \multicolumn{4}{|c|}{$\mathrm{T}=1300^{\circ} \mathrm{C}$} \\
\cline { 2 - 5 } & $\mathrm{Ti}_{\mathrm{s}}$ & $\mathrm{Ti}_{\mathrm{p}}$ & $\mathrm{N}_{\mathrm{s}}$ & $\mathrm{N}_{\mathrm{p}}$ \\
\hline $\mathrm{S} 2$ & 0.012 & 0.009 & 0.0019 & 0.0027 \\
\hline S3 & 0.035 & 0.012 & 0.0007 & 0.0036 \\
\hline S5 & 0.005 & 0.013 & 0.0043 & 0.0037 \\
\hline S6 & 0.010 & 0.021 & 0.0022 & 0.0061 \\
\hline
\end{tabular}

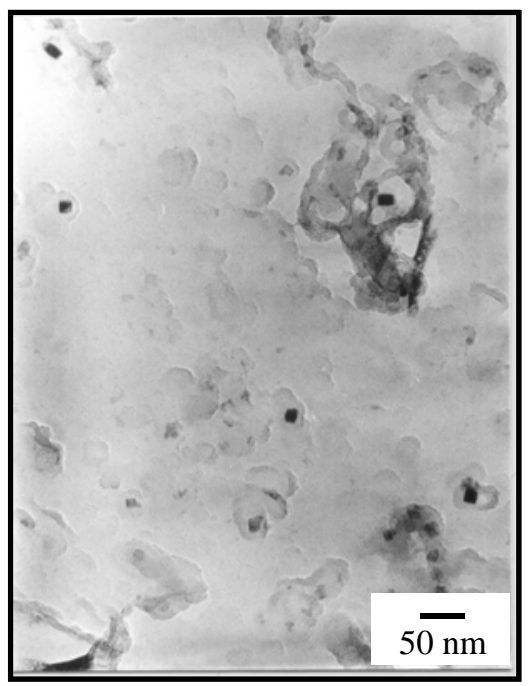

Fig. 1. TEM image of fine TiN particles at $1300^{\circ} \mathrm{Cx} 10 \mathrm{~min}$ for steel S5.

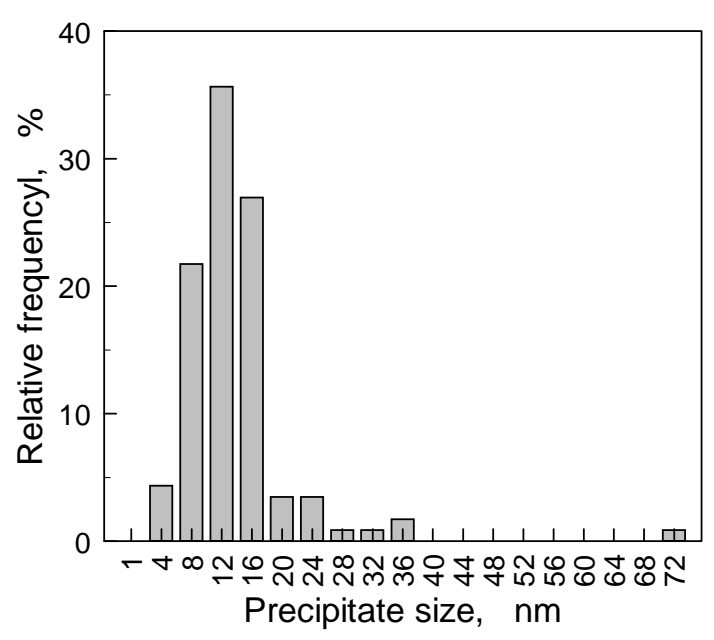

Fig. 2. Relative frequency of TiN fine particles at $1300^{\circ} \mathrm{Cx} 10 \mathrm{~min}$ for steel S3.

\section{Hot Deformation Strength}

Fig. 3 presents an example of the stress-strain curves (flow curves) for steels S4, S5 and S6 obtained for certain testing conditions. The maximum stress value, known as peak stress, indicates the hot strength of the steel when it is deformed. In general, steels S5 and S6 are those which present the highest peak stresses in all the deformation conditions, which means that these steels will present a greater hot deformation strength and therefore the rolling forces to be applied must be greater.

In contrast with what might seem more logical, i.e. that the higher the microalloying element content, the greater the strength, it has been seen that this is not so. Steel S5 has the lowest titanium content but nevertheless presents a greater hot deformation strength than the other steels. The reasons need to be sought in the Ti/N ratio and in their corresponding precipitation state.

Another way of measuring the influence of $\mathrm{Ti}$ and $\mathrm{N}$ on the hot deformation strength is by means of the activation energy. The reason for this is found in the Zener-Hollomon equation [14] which relates the peak stress with the activation energy. Accordingly, the influence exerted by the TiN not 
dissolved at the austenitisation temperatures must be reflected in the activation energy. In order to analyse this relationship, the difference between the activation energy determined experimentally for each steel and that of the base steel has been represented in graph form versus the Ti/N ratio (Fig. 4). As can be seen, the highest activation energies correspond to the steels with ratios of close to 2 . Steel S3 presents a lower energy than steel S1, probably due to the fact that the coarse particles in this steel have served as sources of nucleation of dynamic recrystallisation, thus decreasing the value of the peak stress.

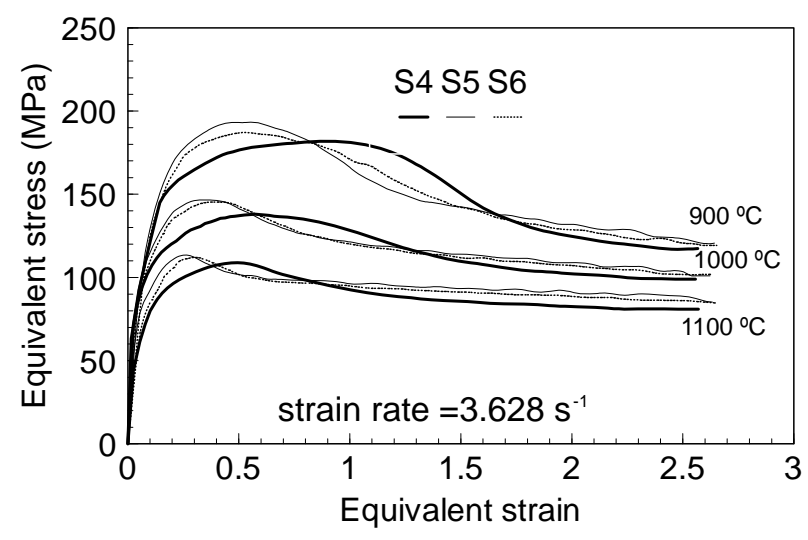

Fig. 3. Flow curves for steels S4, S5 and S6.

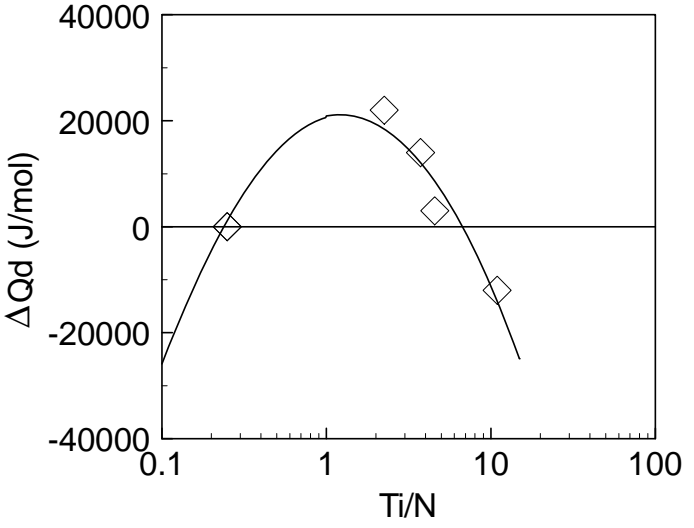

Fig. 4. Activation energy increment for hot deformation against ratio $\mathrm{Ti} / \mathrm{N}$.

\section{Static Recrystallisation}

From the isothermal tests described above and applying the back extrapolation method, recrystallised fraction versus time curves have been obtained. Fig. 5 shows an example corresponding to steel S3. As can be seen, for the temperature of $900^{\circ} \mathrm{C}$ a plateau has been produced which indicates a momentary inhibition of static recrystallisation. This is due to the strain induced precipitation of $\mathrm{Ti}$ and $\mathrm{N}$ which remained in solution at the austenitisation temperature $\left(1300^{\circ} \mathrm{C}\right)$. This inhibition has only taken place in some forming conditions in the steels with the highest titanium content: S3 and S6.

The activation energy for static recrystallisation is determined by representing the time that is taken for $50 \%$ of the volume to recrystallise $\left(t_{0.5}\right)$ versus the inverse of the temperature [9]. To measure the influence of the $\mathrm{Ti} / \mathrm{N}$ ratio on recrystallisation, the difference between the activation energies of each steel and the corresponding base steel has been represented versus the $\mathrm{Ti} / \mathrm{N}$ ratio (Fig. 6), in the same way as for the deformation energy.

In principle it may be thought that steel S3 should have a lower activation energy than the other steels, since its $\mathrm{Ti} / \mathrm{N}$ ratio is much higher than the stoichiometric value and it therefore has a larger precipitate size than the rest of the steels that do not exert an inhibition on the nucleation and growth of the recrystallised nuclei, and therefore may favour this process due to the effect of heterogeneous nucleation. However, steel S3 is the steel with the highest Ti content in solution of all the steels. Given that $\mathrm{Ti}$ has a similar atomic volume to $\mathrm{Nb}$, it is to be expected that it will also have a great influence on the activation energy in static recrystallisation [14]. This would explain why steel S3 has a higher activation energy.

As a consequence of the above, it has not been possible to obtain an expression that relates the activation energy with the $\mathrm{Ti} / \mathrm{N}$ ratio. This indicates that the activation energy not only depends on the $\mathrm{Ti} / \mathrm{N}$ ratio, i.e. on the precipitation state, but also on the $\mathrm{Ti}$ in solution. The results that have been obtained show that the mechanism which regulates the movement of dislocations during the hot 
deformation of austenite is different to that of grain boundary self-diffusion, a mechanism that regulates static recrystallisation, due not only to the different activation energy in the two phenomena but also to the different effects of Ti when precipitated or in solution.

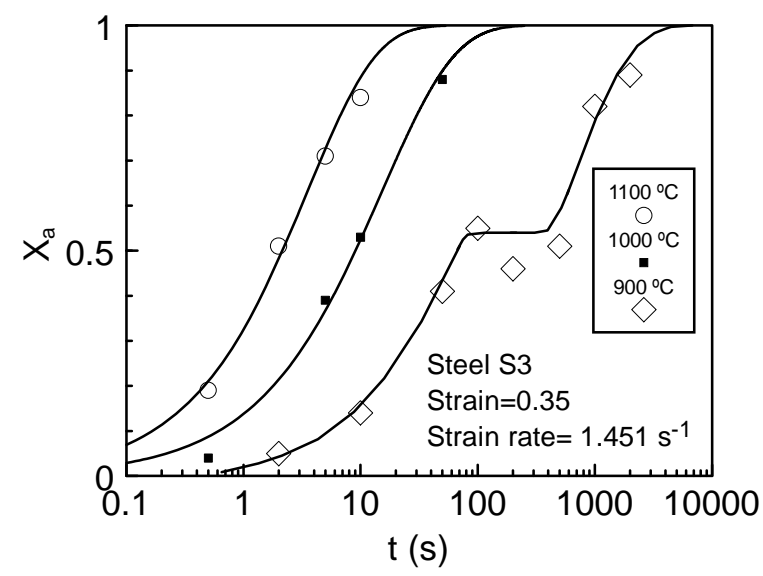

Fig. 5. Variation of recrystallised fraction $\left(\mathrm{X}_{\mathrm{a}}\right)$ with time $\mathrm{t}$ for steel S3.

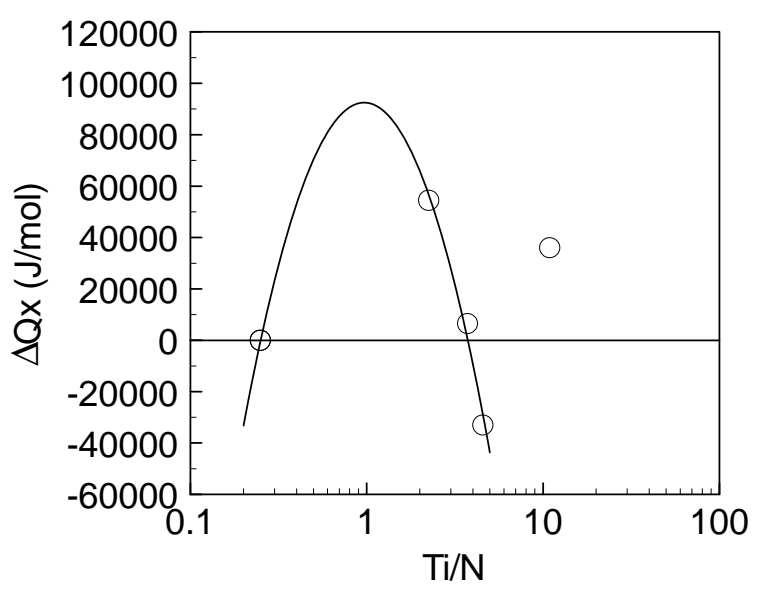

Fig.6. Activation energy increment for static recrystallisation against ratio $\mathrm{Ti} / \mathrm{N}$.

\section{Conclusions}

1. In microalloyed steels an increase in the $\mathrm{Ti}$ content does not necessarily mean that the deformation strength also rises.

2. A relationship has been obtained between the precipitation state and the maximum strength presented by the steels during hot deformation. The influence of the precipitation state affects the value attained by the activation energy, which is at its maximum when the $\mathrm{Ti} / \mathrm{N}$ ratio is close to 2, corresponding to the finest precipitation state.

3. The greatest activation energy for static recrystallisation is achieved for a $\mathrm{Ti} / \mathrm{N}$ ratio close to 1.5. Besides the $\mathrm{Ti} / \mathrm{N}$ particles, $\mathrm{Ti}$ in solution also contributes to notably increasing the activation energy.

\section{References}

[1] E.T. Turkdogan: Iron Steelmaker, Vol. 3 (1989), p. 61.

[2] K. Narita: Trans. Iron and Steel Inst. of Japan, Vol. 15 (1975), p. 145.

[3] C.S. Smith: Trans. AIME, Vol. 175 (1948), p. 15.

[4] T. Gladman: The Physical Metallurgy of Microalloyed Steels (The Institute of Materials, London 1997).

[5] P.E. Reynolds: ISIJ Int., Vol. 34 (1994), p. 689.

[6] F.B. Pickering: Overview of Titanium Microalloyed Steels. Titanium Technology in Microalloyed Steels (The Institute of Materials, London 1997).

[7] R.L. Bodnar: Iron Steelmaker, Vol. 8 (1994), p. 19.

[8] R. Priestner, C. Zhou and A.K Ibraheem: Precipitation in Cast Microalloyed Steel Containing Ti And Nb. Titanium Technology in Microalloyed Steels (The Institute of Materials, London 1997).

[9] S. F. Medina and J.E. Mancilla: Scripta. Metall. Mater, Vol. 30 (1994), p. 73 
[10] J.H. Beynon and C.M. Sellars: ISIJ International, Vol. 32 (1992), p. 359.

[11] A. Faessel: Rev. Metall. CIT, Vol. 33 (1976), p. 875.

[12] H.L. Andrade, M.G. Akben and J.J. Jonas: Metallurgical Transactions A, Vol. 14 A (1993), p. 1967.

[14] S.F. Medina and C. Hernandez: Acta Mater., Vol. 44 (1996), p. 137. 